\title{
La presencia femenina entre los inmigrantes portugueses en Lima en el siglo XVII
}

\author{
Gleydi Sullón BARreto \\ SIHMA \\ gleydisullonb@yahoo.es
}

Recepción: 6 de junio de 2015 / Revisión: 24 de noviembre de 2015

Aceptación: 21 de diciembre de 2015 / Publicación: Diciembre de 2016

\section{RESUMEN}

El paso de mujeres a las Indias estuvo reglamentado por la ley, que amparaba especialmente la emigración de los hombres casados acompañados por sus respectivos cónyuges. No obstante, la documentación revela la presencia de mujeres solteras y viudas que habrían viajado solas o en compañía de otros parientes.

Este trabajo se centra en el perfil de la mujer portuguesa -o de ascendencia portuguesa- que se halló en Lima en el siglo XVII. Fueron pocas en relación con el número de los varones, sin embargo su presencia como cónyuges, hijas, sobrinas o paisanas se hizo sentir en los planos económico y social de la capital virreinal, y algunas -especialmente las hijas habidas en el Perú- habrían facilitado los procesos de integración e inserción de toda una familia en la sociedad limeña.

Las fuentes documentales proceden principalmente de la sección notarial del Archivo General de la Nación en Lima (AGN).

Palabras clave: Inmigración portuguesa, mujeres, viudas, legitimidad, estrategias matrimoniales, Lima, siglo XVII.

\section{Women among the Portuguese Immigrants of Lima in the $17^{\text {th }}$ Century}

\begin{abstract}
The passage of women to the Indies was regulated by Law, as applied especially to married men who migrated with their spouses. Documents, nonetheless, reveal the presence of single women and widows who traveled alone or in the company of other relatives.

This article focuses on the profile of Portuguese women -or women of Portuguese ancestry- found in Lima in the 17th century. Although they were few with respect to the number of men, as spouses, daughters, nieces or fellow countrywomen they had economic and social impact on the Vice-Royal capital. Some -esepcially those born in Peru- facilitated the processes of integration and insertion of entire families into Lima society.

The sources used in this study proceed mainly from the Notarial section of the General Archives of the Nation, in Lima.
\end{abstract}

Keywords: Portuguese immigration, women, widows, legitimacy, marriage strategies, Lima, $17^{\text {th }}$ century. 
SUMARIO: 1. Introducción. 2. Legislación indiana y el paso de las mujeres al Perú. 3. La mujer lusa y sus ámbitos de actuación en el medio social y económico de Lima. 4. Descendencia femenina e inserción social. 5. Consideraciones finales. 6. Referencias bibliográficas.

\section{INTRODUCCIÓN ${ }^{1}$}

En 1656 el comerciante portugués Joan de Nolete declaraba en el testamento, dictado en Lima, una deuda por pagar a doña Guiomar Henriques por un monto de 15.240 pesos, y otra de menor valor a doña Isabel Henriques, hermana de la anterior, por 8.533 pesos y tres reales ${ }^{2}$. El nombre de estas mujeres -de ascendencia portuguesa, aunque nacidas en Sevilla- habría pasado inadvertido si no fuera porque ambas estuvieron vinculadas -indirectamente- con los sucesos de la "complicidad grande" de 1635-1639. Doña Guiomar había estado casada con el capitán Manuel Baptista Peres, y su hermana doña Isabel había sido mujer legítima de Sebastián Duarte. Sabemos que los dos mercaderes y socios perecieron en el auto de fe de 1639 cuando fueron condenados, por judaizantes, a relajación. No obstante las mujeres sobrevivieron al final trágico de sus respectivos cónyuges y diecisiete años después las encontraremos en Lima en una holgada posición económica ${ }^{3}$. Esta realidad revela que ni su condición de viudas -o mujeres solas- ni su ascendencia portuguesa ni siquiera sus vínculos directos con el colectivo judaizante habría afectado a que, como cabezas de familia, tomaran las riendas de la economía del hogar, y se hallaran situadas en un estatus más o menos alto de la sociedad limeña.

El presente artículo se centra en el perfil de la mujer portuguesa, o de ascendencia portuguesa, que se halló en Lima en el siglo XVII. Fueron pocas en relación con el número de los varones para el mismo tiempo, sin embargo su presencia como cónyuges, hijas, sobrinas o paisanas se hizo notar de modo significativo en los planos económico y social de la capital virreinal. Algunas, probablemente, habían viajado solas; otras, en compañía de la familia o para reunirse con el marido en las Indias, lo cierto es que para buena parte de los casos conocidos Lima representó el lugar de su realización económica y la tierra que eligieron para vivir y para morir. No hemos encontrado, en los casos analizados, intentos de retorno.

La fuente documental de donde parte este estudio son principalmente los protocolos notariales conservados en el limeño Archivo General de la Nación (AGN) ${ }^{4}$. Un barrido amplio de esta fuente ha permitido deducir que la inmigración portuguesa a la capital del virreinato peruano fue emprendida principalmente por varones: para

\footnotetext{
${ }^{1}$ Agradezco a Carmen Ruigómez por la sugerencia del tema, y a Pilar Ponce por la motivación para escribirlo. Asimismo, a Pilar Latasa, Ana Isabel López-Salazar y Jaime Forero por haberme facilitado algunas de las referencias bibliográficas incluidas en este trabajo. A Kate Mills, por la revisión del abstract. El texto definitivo de este artículo fue mejorado y enriquecido con los aportes y sugerencias que recibí desde el equipo editorial de la Revista Complutense de Historia de América, lo cual agradezco.

2 Testamento de Joan de Nolete. Lima, 17-X-1656. Archivo General de la Nación en Lima (en adelante AGN), Prot. Not., 1038, Miguel López Varela (1656), f. 1890.

3 Para una aproximación a la familia de Manuel Baptista Peres y Sebastián Duarte, véase Ventura, 2005, v.I, t.I, pp. 347-457.

4 Para una valoración de la fuente notarial, y especialmente del testamento, como medio para el conocimiento de las sociedades virreinales, de su funcionamiento, dinamismo y versatilidad, véase PONCE, 2011.
} 
los años de 1600 a 1680 de un total de 165 inmigrantes portugueses localizados, sólo ocho fueron mujeres. Esta proporción escasa de la mujer lusa en la capital del virreinato peruano -desde la fuente notarial- queda reflejada también en otro tipo de fuentes como son los expedientes matrimoniales, los autos de bienes de difuntos o los libros de entrada y salida de enfermos del Hospital Real de San Andrés, donde los nombres de mujeres portuguesas destacan más bien por su ausencia ${ }^{5}$. Por otro lado, y de acuerdo con el propósito del presente trabajo, hemos incorporado algunas historias de las descendientes de los portugueses que se hallaron en Lima en el mismo periodo, quienes hicieron testamento, formalizaron matrimonios o ingresaron como monjas en los conventos limeños, situación que habría facilitado la integración de la familia en la sociedad.

En cuanto al aspecto metodológico se ha partido del análisis biográfico de cada una de las protagonistas para intentar, en un segundo momento, un estudio colectivo de sus vidas, a partir de ciertas variables comunes como el tiempo de residencia en la ciudad, la actividad económica desarrollada, y sus relaciones y vínculos interpersonales ${ }^{6}$. Esto último muestra la forma de su actuación, el tipo de gente con que trataron, además de sus afectos, querencias y devociones. Una primera aproximación a los datos revela que en su mayoría conformaron los estratos medios de la sociedad, practicaron el comercio a mediana escala, y tuvieron estrecha vinculación con las órdenes religiosas de la ciudad. Por otro lado, las mandas testamentarias dan cuenta de los lazos conservados con la tierra de origen, donde, al parecer, y para el caso de la mujer lusa, fueron más bien escasos.

En las páginas que siguen se explicará, en primer lugar, el marco jurídico que reguló el paso de las mujeres -castellanas y extranjeras- al Perú. Si bien la legislación indiana amparaba la inmigración de los hombres casados acompañados por sus respectivas cónyuges, no fue extraño que algunos de estos inmigrantes -de entre los casados- viajaran solos ${ }^{7}$. Ello explica que las autoridades peninsulares y virreinales emprendieran pesquisas al respecto y procuraran -bajo mandato legal- la reagrupación familiar o el regreso del inmigrante a la tierra de origen, para que el susodicho pueda "hacer vida maridable con su mujer" Lima entre 1570 y 1680 , se ha podido conocer que fueron muy pocos los que habiendo casado en España o en Portugal consiguieron la reagrupación de la familia nuclear,

5 Las mujeres judaizantes -portuguesas o de ascendencia portuguesa- que habrían pasado al Nuevo Mundo "lo hicieron [también] en proporción ínfima con respecto a los hombres de su misma religión". Cfr. GARCÍA, 1966, pp. 240-248.

6 Para una aproximación al análisis de los vínculos interpersonales como modelo explicativo de las sociedades coloniales en América, véase PonCE - AMADORI, 2008, pp. 18-19.

7 Sobre la repercusión de la mayoritaria emigración masculina a las Indias, tanto en las estructuras familiares del Antiguo Régimen como en la vida de aquellas mujeres con sus maridos ausentes, véase GÁLVEZ, 1997, pp. 79-102.

8 Como ejemplo de estas pesquisas véase la seguida por el fiscal de la Real Audiencia de Lima contra el portugués Duarte Gomes de Miranda, residente en Lima, por haber casado en las Indias, estando casado en los reinos de España. El susodicho deberá probar que su primera mujer -la que dejó en España- es difunta. Cfr. Probanzas Duarte Gomes de Miranda, residente en la Ciudad de los Reyes. 1627. Archivo General de Indias (en adelante AGI), Escribanía, 1022C. Por otro lado, conviene anotar que algunas de las denuncias sobre el marido ausente -a causa de su viaje a las Indias- eran iniciadas por las propias mujeres, o sus representantes, ante las autoridades eclesiásticas o civiles. Al respecto véase GÁLVEZ, 1997, pp. 85-88. 
y de éstos, todos los "que habían casado en los reinos de España, pero ninguno de los que habían casado en Portugal"9.

Un segundo aspecto a considerar es el perfil de la mujer portuguesa y sus ámbitos de actuación en el medio social y económico de Lima. Hemos anotado que su número fue bastante exiguo con respecto a los varones, se entiende -como ha quedado demostrado- que la emigración portuguesa se caracterizó por ser "esencialmente individual y masculina", esto supuso, en la sociedad portuguesa de los siglos XVI y XVII, que la estructura tradicional de la familia se viera sustancialmente modificada: "A pouco e pouco passou a existir uma família mais restrita com um aumento notório da mono-parentalidade" ". En ese contexto, la imagen de la mujer que se proyectó en Portugal fue la de una "mulher frequentemente viúva de direito e de facto ou muito simplesmente em estado de viuvez, casada sem marido, viúva de vivo" ". Siendo esto así, es probable que las pocas que cruzaron el Atlántico se hallaran comprendidas -en su mayoría- entre las viudas de hecho y las solteras, según se deduce de los datos analizados.

La tercera parte de este artículo se centrará en la descendencia femenina de los inmigrantes lusos. Es importante anotar que algunos de estos extranjeros se valieron de diversas estrategias para alcanzar la integración en la nueva ciudad como fueron el matrimonio con natural del reino, la inversión en bienes inmuebles -casas, tiendas, bodegas y tierras de sembrar-, su vinculación con las órdenes religiosas de la ciudad, y sus tratos -no necesariamente económicos- con gente de distinta procedencia, naturaleza o etnia. Los que tuvieron descendientes -hijos criollos nacidos en el Perúprocuraron, asimismo, la integración definitiva de la familia en la nueva sociedad, a través de la puesta en estado de los hijos, donde las mujeres -ya como monjas o como casadas-, debían cumplir un papel importante en el cuidado de los otros miembros, y en la preservación del nombre y del patrimonio. El análisis para este propósito se centrará en el estudio de un caso concreto como modelo explicativo de esta realidad.

\section{LEGISLACIÓN INDIANA Y EL PASO DE LAS MUJERES AL PERÚ}

De acuerdo con una consulta del Consejo de Indias en 1607, fueron muchas las razones que llevaron a gentes de toda clase, estado y naturaleza -de entre los naturales del reino y los extranjeros- a emprender el viaje a las Indias:

Muchos por buscar sus comodidades, y otros por negocios y causas forzosas de tener allá padres hijos o parientes que los envían a llamar para favorecerlos y dejarles sus haciendas, y otros a cobranzas, y muchas mujeres a estar con sus maridos, y mer-

\footnotetext{
9 Sullón, 2015, pp. 75-78.

10 MEA, 1995, p. 65.

11 Ibídem, p. 67. Esta realidad llevó a los portugueses de ese tiempo a imaginar la ciudad de Lisboa como "sola casi viuda", aludiendo no sólo a la ausencia del rey, sino para hacer referencia al alto número de sus mujeres solas, a causa de la emigración de sus cónyuges, algunos de los cuales habían pasado al Nuevo Mundo y de los que muchos no retornarían. Agradezco a Rafael Valladares por haberme facilitado esta información. Al respecto véase BouZA, 1998, pp. 95-120.
} 
caderes que, habiendo traído grandes partidas de dineros para emplear, [desean] volver con ellas a aquellas partes ${ }^{12}$.

Esto a propósito de la demanda de licencias tramitadas ante la Casa de la Contratación de Sevilla. Pero ¿cuáles fueron las disposiciones emanadas por la Corona en relación con el paso de las mujeres al Perú, y de forma particular con el paso de las mujeres extranjeras? Una cédula de 13 de noviembre de 1550 había autorizado el viaje de las mujeres al Perú -se entiende de las solteras- siempre que quisieren ir "a poblar y vivir y permanecer en ellas", era intención del monarca hispano consolidar la colonización y la población estable de las nuevas tierras, y una de las formas fue ciertamente con la fundación de nuevas familias. Es probable que surgieran algunos inconvenientes porque una cédula posterior del 8 de febrero de 1575 mandó a los jueces oficiales de Sevilla que no dieran licencias sin orden real a las mujeres solteras ${ }^{13}$. Teóricamente no se prohibió el paso de las mujeres solteras al Perú, la ordenanza indicaba únicamente que éstas requerían de especial licencia real.

En cuanto a las casadas, la política migratoria de la corona española buscó proteger la vida familiar, de ahí que amparara especialmente la emigración de hombres casados llevando consigo a su mujer y la de mujeres casadas acompañadas de los hijos que iban a reunirse con el marido, teniendo éste el permiso correspondiente ${ }^{14}$. Varios ejemplos al respecto han quedado recogidos en los libros de asientos de pasajeros conservados en el AGI, donde se da cuenta de las calidades y circunstancias particulares de los viajeros. Algunos pasaron juntamente con la familia como fue el caso de Juan Baes de Francia, natural de Tavira, quien en 1571 "se despachó al Perú con María Dias, su mujer [...] por cédula de Su Majestad y llevaron consigo a Manuel Baes Pasqual, su hijo soltero" ${ }^{15}$. En otros casos era la mujer quien emprendía el viaje para procurar -en las Indias- la reunión familiar, fue el caso de doña Leonor Nuñes, natural de Évora, quien en 1578, en compañía de sus hijos Jerónimo Gutierres y doña Isabel Juares, "se despachó para el Perú para hacer vida maridable con el doctor Enrique Mendes, su marido [...] no embargante que sean portugueses" ${ }^{16}$. Debieron ser muchos los casos en este sentido ${ }^{17}$, aunque por otro lado, es probable que fueran muchos más los referidos a hombres casados que emigraban al Nuevo Mundo solos, sin

12 Sobre despacho de las licencias para pasar a Indias. Madrid, 8-XI-1607. AGI, Lima, 2, Consultas originales del Consejo, Cámara y Juntas.

13 Cfr. Encinas, 1945 [1596], libro I, ff. 401-402. Para un estudio de la inmigración de mujeres a la América colonial, y a la legislación sobre ello, véase KonETZKe, 1945a, pp.123-150.

14 Cfr. Encinas, 1945 [1596], libro I, ff. 400-401 y 410; Recopilación de Leyes de los Reinos de las Indias (RLI), 1841 [1680], lib.IX, tít.XXVI, leyes XXV, XXVI, XXVIII, XXIX, t.IV, p. 5.

15 Cfr. Asiento de pasajeros de Juan Baes de Francia. 1571. AGI, Contratación, 5537, 1.3, f. 434r. Apud ROMERA - GALBIS, 1980, v.V, t.I, p. 427.

16 Cfr. Asiento de pasajeros de Leonor Nuñes. AGI, Contratación, 5538, L.1, f. 76v. Apud, GaLBIS, 1986, v.VI, p. 28.

17 Un estudio de Blanca López de Mariscal para el caso de Nueva España, entre 1540 y 1625 , da cuenta de numerosos casos en los que el marido reclama la presencia de su mujer en las Indias, ya para evitar el pago de la multa o la cárcel, o simplemente por la nostalgia de la esposa y de los hijos "que se han dejado atrás". LÓPEZ DE MARISCAL, 2013, pp. 73-75. 
procurar la reagrupación de la familia nuclear ${ }^{18}$. La Recopilación de Leyes de Indias de 1680 dedicó un amplio capítulo a reglamentar esta realidad teniendo en cuenta el problema o la situación de abandono en que quedaban muchas mujeres, en España, con los maridos ausentes en las Indias ${ }^{19}$.

El tratamiento sobre la mujer extranjera en la legislación indiana debió seguir la misma política aplicada a los extranjeros en general -se entiende los de género masculino- ${ }^{20}$, es decir, que aun bajo la condición jurídica de extranjeras, éstas estuvieron también entre los pasajeros habilitados para pasar a las Indias. No obstante, interesa anotar que, a diferencia de los varones, otras razones habrían justificado su presencia en suelo americano. De los portugueses sabemos que la corona española los naturalizó y habilitó para el comercio con el Nuevo Mundo ${ }^{21}$, en otros casos facilitó su entrada siempre que resultaran útiles en determinados oficios como marineros, maestres o pilotos ${ }^{22}$, y no faltaron los casos de legalización posterior, a través de las composiciones para aquellos que se hallaban avecindados ${ }^{23}$. En todos los casos la política permisiva de la Corona con respecto a los extranjeros impuso ciertos límites ya fuere en cuanto al caudal con que debían tratar y contratar, el tiempo de permanencia en suelo peruano, o en cuanto a la jurisdicción en la que debían residir, entre otros ${ }^{24}$. Sobre la mujer extranjera las especificaciones en la Recopilación de Leyes de Indias de 1680 son escasas, la única referencia que hemos hallado se recoge en el capítulo relacionado con las composiciones cuando se señalan los casos de excepción, entre otros, el de los clérigos, los extranjeros encomenderos de indios "cuyas encomiendas se hubieren dado por grandes servicios o en casamiento" y las mujeres extranjeras ${ }^{25}$.

Es probable que las mujeres a diferencia de los inmigrantes extranjeros varones no despertaran tanto recelo entre las autoridades virreinales: el comercio de grueso monto, la conformación de redes mercantiles, la ocupación de puestos estratégicos en la marinería y en los oficios mecánicos, estuvo por lo general en manos de los portugueses varones. Además, la sospecha de rebeldía, sobre todo después del levantamiento de Portugal en 1640, o la de judaísmo, en materia religiosa, que tuvo su principal manifestación -en Lima- en el auto de fe de 1639, recayó principalmente entre los sujetos varones. Se entiende que toda la política restrictiva en cuanto a la inmigración

18 Diversas razones habrían explicado la no reagrupación familiar: la escasez de medios económicos del inmigrante para sufragar los costos de viaje de la familia nuclear, el temor de la propia mujer y de los hijos frente a la travesía marítima, o el olvido y abandono real de la familia debido al mucho tiempo transcurrido lejos de la patria de origen. Algunas de estas razones pueden deducirse de la correspondencia privada de los emigrantes. Al respecto véase OtTe, 1996, pp. 25-32; SÁnCheZ - Testón, 1999, pp. 13-33.

19 (RLI), 1841 [1680], lib.VII, tít.III, leyes I-IX.

20 Para una síntesis de la legislación indiana -y de su evolución- relativa a los extranjeros, véase Moreno, 1936, pp. 364-385; KONETZKe, 1945b, pp. 269-299.

21 RLI, 1841 [1680], lib.IX, tít.XXVII, leyes I y III, t.IV, p. 12.

22 Cfr. Encinas, 1945 [1596], libro I, f. 457.

23 RLI, 1841 [1680], lib.IX, tít.XXVII, leyes XIII-XVII, XXIII y XXIV, t.IV, pp. 14 y 15; ANTúNEZ, 1981 [1797], parte V, art.V, pp. 326-328.

24 Para estos límites impuestos a los extranjeros habilitados para viajar, navegar, comerciar o residir en las Indias, véase: RLI, 1841 [1680], lib.IX, tít.XXVII, leyes I, III, IV, V, VI, XX, XXX, t.IV, pp. 12-14, 16; VeiTIA, 1981 [1672], lib.I, cap.XXXI, n.2, p. 237; ENCINAs, 1945 [1596], libro I, ff. 451 y 459.

25 (RLI), 1841 [1680], lib.IX, tít.XXVII, leyes XIII, XVI y XXII, pp. 14-15 
a Ultramar estuviere dirigida a ellos, mientras que ellas, las mujeres extranjeras, al parecer, tuvieron un trato un poco diferente.

Por otro lado, conviene tener en cuenta la situación de dependencia -en términos jurídicos- en que se hallaba la mujer con respecto al hombre ${ }^{26}$. Las informaciones sobre licencias de pasajeros a Indias revelan que el titular de tal merced era, por lo general, el varón adulto; por tanto la mujer, los hijos, otros parientes y los criados que le acompañaban eran incluidos en esa única licencia que portaba el titular. Las referencias sobre la vecindad siguen el mismo patrón. De acuerdo con las Ordenanzas de Descubrimiento, nueva población y pacificación de las Indias de 1573 se entendía por vecino a aquel que tuviere casa poblada y fuere cabeza de familia ${ }^{27}$, normalmente "varones adultos [...] responsables de una unidad política independiente, la familia" 28 . Las relaciones de extranjeros y los registros de portugueses ordenados en todo el Perú como consecuencia del levantamiento de Portugal recogen también los nombres de varones adultos como cabezas de familia ${ }^{29}$. No obstante, como se explicará a continuación, hubo situaciones en las que las mujeres actuaron también como cabezas de familia independientes, verificándose sobre todo -de acuerdo con los documentos- entre las viudas y las solteras mayores de edad, se entiende -de entre estas últimas- las que habían alcanzado independencia de la patria potestad.

\section{LA MUJER LUSA Y SUS ÁMBITOS DE ACTUACIÓN EN EL MEDIO SOCIAL Y ECONÓMICO DE LIMA}

De los 165 inmigrantes portugueses que hemos localizado en más de 30 escribanías diferentes, para los años de 1600 a 1680, sólo ocho fueron mujeres, es decir, el 4,85\% del total conocido ${ }^{30}$. Es probable que algunas más hubieren transitado por suelo lime-

\footnotetext{
26 Para un estudio de la situación jurídica de la mujer en tiempos de la expansión portuguesa, véase HesPANHA, 1995, pp. 53-64.

27 Transcripción de las Ordenanzas de Descubrimiento, nueva población y pacificación de las Indias, 1973 [1573], cap.93, pp. 70-71

28 La mujer en este concepto -y como miembro de una familia- obtenía algunos beneficios de vecindad por dependencia. De acuerdo con Tamar Herzog las mujeres disfrutaban primero de los derechos ligados "al estatus de vecindad de sus padres", y después del matrimonio "obtenían algunos de los privilegios ligados al estatus de sus esposos", HerzoG, 2006, p. 58.

29 El bando ordenado por el virrey marqués de Mancera en 1642 mandaba el registro de todos los portugueses que hubieren en los distintos corregimientos del Perú, "con declaración de nombre, apellido, naturaleza, edad, oficio, estado, hacienda y familia y el tiempo que ha que entraron en este reino y con qué licencia, pena de la vida y perdimiento de todos sus bienes". De esto se deduce que quedaron comprendidos en esta orden únicamente los portugueses de origen -residentes y estantes-, cabezas de familia -algunos probablemente vecinos-, pero no sus descendientes -criollos nacidos en el Perú-, que de acuerdo con la ley de 20-VIII-1620 eran reconocidos ya por naturales del reino. Cfr. Padrón de portugueses en el corregimiento de Piura. 1642. Archivo Regional de Piura (en adelante ARP), Corregimiento, leg. 5, exp. 63, f. 1; RLI, 1841 [1680], lib.IX, tít.XXVII, ley XXVII, t.IV, p. 15.

30 La fuente inquisitorial revela, por otro lado, la escasa presencia de la mujer lusa entre los procesados por el delito de judaísmo. De los 63 judaizantes penitenciados en el auto de fe de 1639, 46 eran portugueses $(73,02 \%) ; 12$ habían nacido en los reinos de España o en las Indias, pero de ascendencia portuguesa (19,05\%), y únicamente cinco tenían origen español. De los siete absueltos, tres fueron portugueses. De todo este conjunto se mencionan únicamente dos mujeres de ascendencia portuguesa que fueron reconciliadas con sambenito. Cfr. Medina, 1887, t. II, cap. XVIII, pp. 127-156.
} 
ño como consta en los expedientes matrimoniales conservados en el Archivo Arzobispal donde se recoge, por ejemplo, que el portugués Francisco Alvares de Olivera había casado con María Magdalena Lopes, natural de la ciudad de Portalegre ${ }^{31}$. La conclusión que se desprende de estos datos es que aun cuando la población femenina en la Lima del siglo XVII, al parecer, había experimentado cierto aumento ${ }^{32}$, el número de las lusas -en ese contexto- fue realmente bajo. Esto no significa que la mujer portuguesa no se hubiere atrevido a surcar los mares como sí lo habían hecho sus pares castellanas ${ }^{33}$, lo que pasa es que su llegada a las Indias españolas estuvo revestida de otras características del que hubiera supuesto su viaje al Brasil, al África occidental o a la India portuguesa. En el primer caso pesaba su condición de extranjeras. Pero, ¿puede explicarse bajo esta sola premisa la ausencia de registros o nombres de las mujeres lusas en los archivos históricos de Lima y de Sevilla?

En primer lugar, conviene tener en cuenta la situación de clandestinidad que rodeó el viaje de los pasajeros a Indias en general: no todos -ni todas- contaron con la autorización oficial para pasar ${ }^{34}$. En segundo término -y atendiendo a la cuestión religiosa-, es probable que algunas de estas mujeres se hallaran comprendidas dentro de la población judeoconversa, que, como consecuencia de la unión de reinos en $1580^{35}, \mathrm{y}$ del perdón general de $1605^{36}$, habría experimentado una gran movilidad hacia los reinos de Castilla, y aun hacia las Indias, siempre con carácter de reserva y ocultación. Por último, no se puede ignorar el proceso de asimilación que alcanzaron muchas de ellas, y que seguramente con los años, y en virtud de sus estrategias de integración, llegaron a ser pensadas y tratadas, por los otros limeños, como parte de una misma comunidad, y no como extranjeras.

Para el tema que se analiza, ¿qué razones habrían llevado a estas mujeres a emprender el viaje al Perú, y más aún a fijar su residencia en la Ciudad de los Reyes? De los ocho casos conocidos sabemos que una era esclava, por tanto su presencia en la ciudad obedeció a otros factores. Del número restante es probable que hubieren viajado para cumplir un proyecto familiar o económico, lo cierto es que su actuación en la Ciudad de los Reyes como mujeres autónomas -ya en la gestión de sus negocios o en la administración y disposición de sus bienes-, sugiere que se hallaban totalmente integradas en el medio. La mayoría se situó en los estratos medios de la sociedad, formaron parte de hermandades y cofradías, y mantuvieron estrechos vínculos con

31 Expediente matrimonial Francisco Alvares de Olivera y María Magdalena Lopes. Lima, X-1638. Archivo Arzobispal de Lima (en adelante AAL), leg. IX, exp. XLII.

32 Para una aproximación al número de mujeres -o una referencia sobre ellas- en el contexto de la población limeña de las primeras décadas del siglo XVII, véase: SALINAS, 1631, Discurso II, pp. 229-230; LóPEZ De Caravantes, 1986, v.2, p. 16; CoOK, 1968, pp. I-XIII; Durán, 1994, pp. 55-57; LATASA, 1997, p. 41; VAN DEUSEN, 2007, p. 172; GómEZ-LuCENA, 2013, pp. 49-56.

33 Para un estudio de la presencia femenina lusa en los viajes de expansión portugueses de los siglos XVI y XVII, véase: Hutchinson, 1995, pp. 181-186; Miceli, 1995, pp. 187-196. Para el caso específico de su presencia en la India: D’ARmadA, 1995, pp. 197-230. Para el caso de Brasil: KLAwe, 1995, pp. 253-258.

34 Algunos, incluso, habrían pasado con una identidad falsa, lo cual dificulta aún más su localización o identificación real en el Nuevo Mundo. Al respecto véase: TeSTón-SÁnchez, 2010, pp. 87-101. Agradezco a ambas autoras por haberme facilitado la referencia para la consulta de este artículo.

35 Para un análisis del proceso de unión de reinos, remitimos al trabajo de VALLADARES, 2008.

36 Sobre la negociación del perdón general de 1605, y su repercusión en los movimientos migratorios de los judeoconversos portugueses, véase LópeZ-SALAZAR, 2010. 
las órdenes religiosas. Hubo algunas que fundaron, en esta ciudad, memorias perpetuas. Definitivamente, objetivos económicos o proyectos familiares -algunas se vieron rodeadas de parientes y paisanos- habrían impulsado el viaje a las Indias. Poco sustento tienen, por otro lado, y para este caso específico, razones de tipo religioso en la inmigración, o el simple viaje a la aventura.

El tiempo de su presencia en Lima se situó entre 1617 y 1653, lo que sugiere que probablemente habían arribado a tierras peruanas en las últimas décadas del siglo XVI, o en la primera del XVII. Corresponde este tiempo a los años de unión de reinos, que propiciaría, entre otros, la entrada masiva de portugueses -como nuevos vasallos- a las Indias españolas. Para el caso de las protagonistas de esta historia sabemos que una de ellas, doña Catalina de Acuña, ya se encontraba en Lima en 1588. Viuda de Lucas de Aranda, habría arribado al Perú, seguramente, en alguna comitiva y como doncella soltera. Es probable que hubiera contraído matrimonio en el Perú, y decidiera fijar su residencia en la ciudad de Lima, donde sabemos que, en 1588, nació su único hijo Francisco de Acuña, quien sería más tarde "escribano de Su Majestad y de provincia" 37 , y el que probablemente protocolizara el mayor número de escrituras de los portugueses limeños entre 1626 y 1664 . Procedentes en su mayoría de Lisboa -aunque otras venían del Algarbe, Santarén, Évora y Torre de Moncorvo-, habrían entrado seguramente por la vía de Panamá. Fue el caso de Leonor de Melo, de quien sabemos que casó en esa ciudad con el capitán portugués Manuel Lopes. Ambos, en compañía de sus cuatro hijos legítimos, se encontrarán en Lima en 1616, ocupando "unas casas principales en la calle que va del convento de señor San Agustín a la recoleta del convento de Santo Domingo", que para tal efecto había adquirido el dicho capitán Manuel Lopes ${ }^{38}$.

Hemos anotado antes que uno de los rasgos que caracterizó a estas portuguesas fue su capacidad de adaptación e integración en la nueva ciudad. Eligieron por zonas de residencia las parroquias de Santa Ana e Iglesia Mayor, y también el barrio de San Lázaro, lo que supone que crearan vínculos interpersonales con los otros vecinos -naturales del reino y otros extranjeros-, y desarrollaran también cierto sentido de pertenencia ${ }^{39}$. No todas fueron, sin embargo, propietarias de inmuebles ${ }^{40}$. Lo frecuen-

37 Confirmación de oficio de Francisco de Acuña. 1617. AGI, Lima, 182, n.13, f. 1.

38 Poder para testar Manuel Lopes a Leonor de Melo y Martín Fernandes. Lima, 1-I-1616. AGN, Prot. Not. 1735, Diego Sánchez de Vadillo (1616), ff. 2207r-2211.

39 En 1617 María de Melo, no obstante que se mandó enterrar en el limeño convento de San Francisco, pidió que el acompañamiento del cuerpo en el funeral estuviere a cargo del "cura y sacristán de la parroquia de San Lázaro donde vivo". Mandó, además, una limosna generosa para la cera del Santísimo Sacramento de esta misma iglesia. Cfr. Testamento de María de Melo. Lima, 8-VIII-1617. AGN, Prot. Not. 169, Agustín de Atencia (1615-1617), ff. 217-220v. En el presente artículo, la grafía procedente de la fuente documental ha sido modernizada.

40 Conocemos sólo un caso, el de Leonor de Melo, viuda del capitán Manuel Peres, quien en 1624 declaró por suyas dos casas "las unas casas principales [...] en la calle que llaman de la Amargura, y las otras, a la vuelta en la calle que va a la plazuela de San Diego, las cuales son mías y me pertenecen por haber ejecutado en ellas [...] mi dote". Hemos podido conocer por el testamento de su difunto marido que dicha dote sumó 15.000 pesos de a nueve reales, y la escritura había pasado ante escribano público en la ciudad de Panamá. Cfr. Testamento de Leonor de Melo. Lima, 26-III-1624. AGN, Prot. Not. 1756, Diego Sánchez Vadillo (1624), f. 698; Poder para testar Manuel Lopes a Leonor de Melo y Martín Fernandes. Lima, 1-I-1616. AGN, Prot. Not. 1735, Diego Sánchez de Vadillo (1616), f. 2209v. 
te fue más bien el alquiler de aposentos o cuartos en casas de conocidos o amigos, como sucedió en el caso de Juana de Melo, quien en 1622 declaró haber vivido "en un cuarto de la casa de doña Francisca Fernández de Córdova, viuda de don Antonio Ordóñez de Valencia, tiempo de dos años y cinco meses, a razón de cuatro pesos de a ocho reales cada mes" ${ }^{\prime 4}$. El espacio interior de la casa -ya fuere ésta propia o alquilada- representa para el tema que nos ocupa el primer ámbito de sus relaciones sociales.

De las ocho mujeres conocidas dos eran solteras -una esclava, y la otra, beata de Nuestra Señora del Carmen-; cinco estaban viudas, aunque sólo dos de ellas tuvieron hijos dentro del matrimonio, fueron los casos ya citados de Catalina de Acuña y Leonor de Melo; y hubo una que no especificó en el testamento su estado civil, aunque sí declaró un hijo suyo, ya fallecido en 1622, que estaba enterrado "junto al púlpito" en la Iglesia Mayor de Lima ${ }^{42}$. De estos datos se desprende que hubo entre las lusas limeñas una especial inclinación hacia el matrimonio, aunque al momento de testar se hallaran ya viudas. Por otro lado, se comprueba que más de la mitad de estas mujeres no tenían descendencia propia. Por último, la ilegitimidad -en cuanto a su origen o al de su descendencia- no parece haber estado presente en la vida de estas mujeres: con excepción de la esclava, cuyo origen familiar se desconoce, las siete restantes declararon ser hijas legítimas habidas en legítimo matrimonio; y ninguna reconoció haber tenido hijos naturales o ilegítimos ${ }^{43}$.

Estas mujeres -aun las que no tuvieron descendencia-, no se hallaron solas en la ciudad. Algunas refieren la presencia de hermanos o sobrinos que les han ayudado en los momentos de enfermedad, y serán, posteriormente, reconocidos en el testamento. Otras seguramente buscaron compañía entre las esclavas y niñas o niños -algunos huérfanos-, que habían acogido y criado en su casa; en otros casos hubo en el entorno más próximo de estas lusitanas personas particulares -entre amigos o los propios inquilinos- que les habían brindado protección y confianza. Es decir, que el espacio destinado a ser la casa familiar representó, para estas mujeres, el primer ámbito de sus relaciones interpersonales y donde se crearán vínculos de muy variada naturaleza. María de Melo, natural de Tavira, declaró en 1617 haber sido casada con Antonio Casco de Cana y que durante el matrimonio "no hemos tenido ni tenemos hijos ningunos", no obstante, había acogido y criado a tres niños, no necesariamente huérfanos: "María de Sotomayor, hija de don Alonso de Sotomayor [...] que será de edad de trece años poco más o menos", Constanza de Herrera "moza que tengo en mi casa", y Pedro "niño que será de edad de cinco años poco más o menos", todos ellos serán incluidos en el testamento con limosnas generosas para su crianza o para cuando tengan edad de tomar estado. Contó también con la compañía de un sobrino suyo, Antonio de Mendosa, de quien reconoce deberle mucho "por lo que ha gastado conmigo en mi enfermedad", a él le será confiada la crianza del niño Pedro, y le legará prácticamente todo lo que quedare de sus bienes, una vez cumplidas las mandas. Hubo otra persona

\footnotetext{
41 Testamento de Juana de Melo. Lima, 3-XII-1622. AGN, Prot. Not. 1916, Gerónimo de Valencia (1622), f. 697.

42 Testamento de Juana de Melo. Lima, 20-XI-1620. AGN, Prot. Not. 832, Francisco Hernández (1620), f. $2422 \mathrm{v}$.

43 Para una aproximación al concepto de legitimidad -asociado al honor-, y una amplia referencia a los numerosos casos de ilegitimidad en la Lima del siglo XVII, véase ManNarelLI, 2004, pp. 159-191.
} 
cercana al entorno de María de Melo, como fue doña Agustina de Tovar, quien -junto con Antonio de Mendosa- será su albacea y la tenedora de sus bienes. No conocemos el vínculo que unía a ambas mujeres, más que la confianza; y precisamente en virtud de esa confianza nuestra portuguesa había dado a guardar a la susodicha determinada cantidad de pesos, algunos bienes muebles, objetos religiosos y de plata labrada, unas pocas joyas, y diversos artículos textiles, todo en su conjunto debía servir para pagar el testamento, y por tanto habían de incluirse en el inventario ${ }^{44}$.

La lectura de este caso nos ha permitido conocer, por otro lado, dos situaciones que fueron comunes al conjunto de la muestra. La primera es que las referencias a la memoria del marido muerto son prácticamente nulas o escasas en los testamentos: más allá de una breve mención a su nombre al momento de declarar el estado civil, no existe mayor información sobre los susodichos; ni siquiera son incluidos en las mandas de misas de sufragio por su alma. La segunda es que, al parecer, ninguna de las mujeres lusas que habían enviudado volvió a casar. Llama la atención este dato por cuanto no fueron raros en la América colonial los matrimonios en segundas nupcias $^{45}$, más aún cuando existen indicios de que algunas de estas mujeres enviudaron bastante jóvenes. Es probable que hubiere influido el contexto barroco de la época que insistía en la práctica del recogimiento y la virtud para las mujeres viudas ${ }^{46}$, y aunque ninguna ingresó a casas de recogimiento, sí nos consta que en su totalidad las viudas de la muestra estuvieron vinculadas con hermandades y cofradías, con el clero secular y con los representantes de las órdenes religiosas. Buscaban acaso paz, consuelo y sosiego espiritual que sólo las cosas de Dios podían ofrecer.

Con excepción de la Compañía de Jesús, estas mujeres se hallaban vinculadas con las restantes órdenes religiosas: San Agustín, San Francisco, Santo Domingo y la Merced. María de Melo, por ejemplo, había ingresado como "religiosa profesa de la tercera Orden de San Francisco" que, al parecer, estuvo dirigida a personas seglares de entre los solteros, casados o viudos; y atrajo preferentemente a los sectores mejor acomodados del medio ${ }^{47}$. Se entiende que el ingreso a esta hermandad franciscana suponía el cumplimiento de determinados compromisos económicos, a cambio de beneficios espirituales, y aun de la posibilidad de disponer -en el interior del convento-, de sepultura propia el día del fallecimiento ${ }^{48}$. Razones espirituales habrían llevado, por otra parte, a Luisa de Jesús Fernandes a integrarse hasta en ocho cofradías y esclavitudes, fundadas en conventos religiosos o iglesias parroquiales de la ciudad. Sabemos de Luisa de Jesús que ya se encontraba en Lima en 1631, y que prolongaría su residencia en esta ciudad por lo menos hasta 1653, año en que dictó un segundo testamento "estando sana y buena por la misericordia de Dios". Natural de Évora, es

44 Cfr. Testamento de María de Melo. Lima, 8-VIII-1617. AGN, Prot. Not. 169, Agustín de Atencia (16151617), ff. 217-220v.

45 Aunque no contamos con datos estadísticos exactos, se observa en los expedientes matrimoniales, en las cartas de dote y en los testamentos -correspondientes, todos los revisados, a la primera mitad del siglo XVII-, que varios de los matrimonios concertados o declarados en Lima, se habían cumplido en segundas nupcias.

46 Para una aproximación al concepto de recogimiento como concepto teológico y como virtud en el tiempo que nos ocupa, véase VAN DEUSEN, 2007, pp. 15-22.

47 Testamento de María de Melo. Lima, 8-VIII-1617. AGN, Prot. Not. 169, Agustín de Atencia (16151617), f. 217.

48 Ibídem, ff. 217-217v. 
probable que optara por llevar una vida de soltera, como "beata de Nuestra Señora del Carmen", se entiende que esta institución debió tener un carácter seglar por cuanto nuestra portuguesa vivía en medio del mundo, y en residencia particular ${ }^{49}$. En uno y otro caso, se observa la intención de estas mujeres por llevar una vida de recato -aunque no por ello menos sociable-, y por aspirar -a través de la limosna y de otras obras de misericordia- a las primicias del cielo. En este contexto es importante subrayar el trato cercano sostenido por nuestras portuguesas con los hombres de la Iglesia: tres de ellas eligieron por albaceas testamentarios a determinados religiosos o clérigos seculares, seguramente amigos o personas de confianza; otras dos los tuvieron en cuenta a la hora de encargar las misas de sufragio por su alma, y finalmente, una de nuestras lusas, Luisa de Jesús Fernandes, mandó a fray Pedro Ramón, de la Orden de Predicadores -su confesor y uno de sus albaceas-, "un santo Cristo crucificado de bulto" ${ }^{50}$. Estas relaciones grafican no sólo su cercanía con las instituciones religiosas de la ciudad, sino la capacidad de integración de estas extranjeras.

En lo que respecta a la actividad económica desarrollada, las fuentes revelan que en su mayoría practicaron el comercio a pequeña escala. El ámbito de su actividad fue principalmente Lima, aunque a través de terceros llegaron también a otras partes como Guaylas, el valle de Chincha, Tierra Firme y los reinos de España. Es probable que traficaran con diversos géneros de mercadería, como artículos textiles u objetos de plata labrada. También sabemos que algunas alternaron este comercio con el préstamo de capital. Pero sin duda, el negocio en el que mayormente destacaron los portugueses, y que los consagró como los más experimentados -por lo menos hasta 1640-, fue el comercio de esclavos, y las lusas de la muestra -aunque fuere a pequeña escala- no fueron ajenas a esta actividad. Por los datos recogidos sabemos que, en su mayoría, las mujeres de la presente historia estuvieron en posesión de algunas piezas de esclavos; y que no fueron pocas las que establecieron vínculos económicos con conocidos mercaderes de este género: los hermanos Gomes Fariñas, Manuel Baptista Peres y Pedro Gerónimo de Melo, este último era hijo de doña Leonor de Melo, quien representa para el conjunto de la muestra la mujer de mayor caudal, y probablemente la única que se involucró de manera casi exclusiva con el tráfico de esclavos ${ }^{51}$.

Doña Leonor de Melo había llegado a las Indias, seguramente, en las últimas décadas del siglo XVI, y es probable que hubiere pasado como doncella soltera, pues sabemos que contrajo matrimonio en Panamá con el capitán portugués Manuel Lopes Serreño de Torres, natural de Viana de Caminha, con quien tuvo cuatro hijos legítimos. Esta portuguesa debió proceder de una familia acomodada, si tenemos en cuenta que el monto de la dote entregada en el casamiento ascendió a poco más de 15.000 pesos de a nueve reales. En 1616 la situamos en Lima cuando el capitán Lopes Serreño de Torres, su marido, hallándose "enfermo del cuerpo", le otorgó carta poder

49 Testamento de Luisa de Jesús Fernandes. Lima, 28-VI-1653. AGN, Prot. Not. 1724, Nicolás Sánchez Márquez (1649-1657), ff. 1324-1325v.

50 Ibídem, f. 1325.

51 Conviene anotar, sin embargo, que en los casos analizados no hubo "mujeres de negocios", entendidas como grandes comerciantes de esclavos, destacaron más bien las de pequeño y mediano caudal, que invirtieron en diversos géneros, y vendieron -seguramente de forma ocasional- uno o dos esclavos. 
para testar y la nombró por una de sus albaceas y la tenedora de sus bienes ${ }^{52}$. Viuda desde 1616 y hasta 1639, año de su fallecimiento, asumió -como cabeza de familia- el gobierno y la administración del hogar. No volvió a casar, y si bien quedó a cargo de una familia numerosa, la herencia que el padre legó a los hijos no fue despreciable, entre otros bienes se enumeran: cinco esclavos, varios bienes muebles y "unas casas principales $[\ldots]$ y otras más pequeñas a la vuelta en la calle que baja de la plazuela de señor San Diego a el camino del Callao". Dejó también una deuda por pagar a varios comerciantes del medio que, en 1616 , sumó 4.000 pesos de a ocho reales ${ }^{53}$. A la muerte del marido, Leonor de Melo debió disponer de sus bienes dotales, y es probable que con parte de ese capital decidiera invertir en la compra-venta y en el alquiler de esclavos.

En 1624 nuestra portuguesa dictó testamento "estando enferma del cuerpo", y aunque su muerte no se dio sino hasta 1639 , los términos de ese único testamento no se modificaron. Para ese año, tres de sus cuatro hijos legítimos eran mayores de 25 años, y por tanto fueron nombrados en el testamento como albaceas: Pedro Gerónimo de Melo, Gabriel Serreño y doña Francisca de Melo. Es probable que los dos primeros se hallaran ya casados y vivieran en casa independiente de la de la madre, pues consta en la documentación que en 1624 doña Leonor de Melo vivía -en unas casas principales en la calle de la Amargura-, únicamente con dos de los hijos: doña Francisca de Melo, doncella soltera, y Nicolás de Melo, "niño enfermo y tullido", de 12 años de edad $^{54}$. Aunque la hija trabajaba en labores de costura, con lo que seguramente pudo comprar, entre otros, escritorios, sobrecamas, joyas y vestidos, los mayores ingresos para el sostenimiento del hogar procedieron principalmente de la actividad comercial de la madre.

En efecto, Leonor de Melo tuvo tratos económicos con Martín Fernandes y Pedro Gerónimo de Melo. El primero, comerciante y amigo de su difunto marido, había realizado -en cabeza propia y como si fueran verdaderamente suyos- algunas transacciones que pertenecían a la susodicha. El segundo de los nombrados, descrito en 1626 como "alto de cuerpo, moreno de rostro y con un lunar debajo de la barba al lado izquierdo", era su hijo legítimo. Aunque de padres portugueses, había nacido en Lima, y fundado su casa y familia en esta ciudad. Dedicado al comercio de géneros de Castilla -y de esclavos desde Tierra Firme-, realizó varios viajes a los reinos de España con el fin de emplear en la ciudad de Sevilla "cantidad de barras de plata y reales", y de comprar mercadurías "para navegar a los dichos reinos del Perú" 55 . Es probable que en uno de esos viajes, el que realizara en 1624 acompañado de su esclavo, Antón Bran, y de un cajero, Martín de Sarreta, llevara junto con su caudal, hacienda que pertenecía a su madre, pues en ese año Leonor de Melo declaró haber

52 Poder para testar Manuel Lopes a Leonor de Melo y Martín Fernandes. Lima, 1-I-1616. AGN, Prot. Not. 1735, Diego Sánchez de Vadillo (1616), ff. 2207-2211.

53 Ibídem, ff. 2209v-2210v.

54 Testamento de Leonor de Melo. Lima, 26-III-1624. AGN, Prot. Not. 1756, Diego Sánchez Vadillo (1624), ff. 697-701.

55 Expediente de información y petición de licencia de Pedro Gerónimo de Melo, mercader, vecino de Lima, con Antón Bran, negro esclavo y con Martín de Sarreta, cajero, para pasar al Perú. Sevilla, 14-II-1625. AGI, Contratación, 5392, n.19, ff. 1-2v; Expediente de información y licencia de pasajero de Pedro Gerónimo de Melo mercader, a tierra firme. Sevilla, 15-IV-1626. AGI, Contratación, 5395, n.2, ff. 1-3. 
entregado a Pedro Gerónimo de Melo la cantidad de 3.500 pesos de a ocho reales que el susodicho debía emplear en España ${ }^{56}$. Este mismo mercader le proveía de esclavos desde Tierra Firme, consta en los documentos que en una ocasión nuestra portuguesa le había entregado 1.500 pesos de a ocho reales para que fueran invertidos en la compra de dos negras angolas y un esclavo ${ }^{57}$, no sería el único encargo. Al momento de testar Leonor de Melo estaba en posesión de hasta 12 piezas de esclavos, entre negras, negros y mulatos. Se entiende, por el número de piezas incluidas en el testamento, que el comercio de esclavos practicado por esta mujer -aunque como actividad principal- debió cumplirse a pequeña escala, no obstante supo sacar mayor rendimiento de ellos, dotándoles de oficio y alquilándolos por jornaleros o marineros ${ }^{58}$. Con este caso hemos querido mostrar la independencia económica de esta viuda que -como otras que se hallaron en Lima- supo fundamentar el éxito de sus negocios en los vínculos familiares y de paisanaje.

En lo que respecta a su última voluntad, Leonor de Melo llamó en la sucesión de la herencia a sus cuatro hijos legítimos, pero decidió mejorar "en el tercio y remanente del quinto de todos mis bienes, derechos y acciones" a su hija Francisca de Melo, a quien nombró también por tenedora de bienes; a ella misma le fue confiada la tutoría y curaduría de la persona y bienes del pequeño de la familia, Nicolás, por razón de ser niño "enfermo y tullido y simple y [tener] necesidad de persona que le cure y limpie con amor y caridad". Pocas fueron, por otro lado, las donaciones destinadas a terceros, únicamente se menciona una limosna de 100 pesos de a ocho reales que la dicha Leonor de Melo legó a una joven doncella nombrada Mencia de Mercado para cuando tenga edad de tomar estado. La Iglesia se benefició también con otros donativos bajo la forma de limosnas por misas de sufragio, y por el costo que supuso su entierro en la capilla mayor de la Iglesia de la Merced; y aunque no se integró en cofradía alguna, como sí lo había hecho su difunto marido, encargó por su alma las misas de san Gregorio y otras 200 que debían decirse en distintos altares, y por los sacerdotes que fueren del parecer de los albaceas. No dejó deudas por pagar, pero sí varias a favor que constaban en sus libros de cuentas. Fue parca en la enumeración de sus bienes muebles -de los que manda se hiciere inventario-, y describió con mayor detalle los bienes inmuebles y los esclavos, eran por cierto los de mayor valor en el conjunto de su patrimonio ${ }^{59}$.

Sobre esta mujer resta por anotar un detalle que revela la firmeza de su actuación como mujer de negocios, que supo distinguir muy bien los tratos económicos de los asuntos de familia: aunque nuestra portuguesa decidió legar el íntegro de su hacienda a los hijos legítimos "para que los hayan y lleven por iguales partes", no dudó en mandar "se pida y tome cuenta con pago de ellos" a Pedro Gerónimo de Melo de los empleos realizados en España por cuenta de la madre; a Francisca de Melo, a quien mejoró en el tercio del quinto de sus bienes, le mandará una esclava, Mauricia,

56 Testamento de Leonor de Melo. Lima, 26-III-1624. AGN, Prot. Not. 1756, Diego Sánchez Vadillo (1624), f. 699.

57 Ibídem, f. 698.

58 De los 12 esclavos, dos habían sido alquilados por marineros en el navío de Juan de Arrasti, en Panamá, ganando cada uno "dieciocho patacones cada mes, horros del capital”. Ibídem, ff. 698v-699.

59 Ibídem, ff. 697v, 700-700v. 
criolla, siempre que pague por ella "el precio que valiere", no siendo así, esta esclava debía venderse en almoneda pública ${ }^{60}$. El sentido de justicia habría primado en el proceder de nuestra lusitana.

En cuanto al trato establecido por el colectivo analizado con gente de otro grupo étnico -indios, negros o mulatos- podemos afirmar que la población indígena estuvo ausente en el entorno social de estas mujeres ${ }^{61}$, los que sí tuvieron mayor presencia fueron los negros esclavos, y no sólo por su condición de bienes, sino porque muchos de ellos -y en virtud del afecto que despertaron en sus dueñas-, se vieron beneficiados generosamente en el testamento. En su mayoría, las portuguesas que estuvieron en posesión de esclavos contemplaron alguna manda a su favor, siendo las más frecuentes la concesión de la libertad -en algunos casos con condición-, o el pago de la misma a muy bajo precio. Se entiende que las mandas así contempladas respondieron a vínculos afectivos "porque la he criado en mi casa y la he querido y quiero mucho", o al interés de velar por su virtud "yo la encargo se recoja en casa virtuosa, pena de mi maldición" ${ }^{62}$. Cuando la manda de libertad estuvo sujeta al servicio temporal -de dos a cuatro años- en casas de particulares o en determinados conventos religiosos, nuestras lusas no dudaron en recomendar -o rogar más bien- a esos nuevos propietarios temporales el que les dispensaran de un buen trato ${ }^{63}$. Es importante destacar -a través de las mandas destinadas a esclavos- la cercanía habida entre nuestras lusas y las órdenes religiosas: la mitad de las propietarias había mandado a los conventos religiosos -Santa Clara y Santísima Trinidad- el servicio temporal de algunos de sus esclavos.

La mayor parte de la vida de estas portuguesas, al parecer, había transcurrido en suelo limeño, lo que probablemente explique los escasos vínculos con la tierra de origen. De los casos conocidos tres portuguesas incluyeron en las mandas de misas de sufragio algunas destinadas a sus padres y otros parientes, y sólo una de ellas contempló una donación pecuniaria para una sobrina en Portugal. Fue el caso de Luisa de Jesús Fernandes quien mandó, en 1631, 300 pesos "a Francisca de Castro, mi sobrina, que está en mi lugar, y mando le envíen luego en la primera ocasión para cuya costa mando [...] otros treinta pesos" ${ }^{\prime 4}$. Sobre este caso es preciso decir que si bien la donación enviada a Portugal fue incluida en el testamento de 1631, en el posterior -dictado en 1653- no existe referencia alguna a aquella sobrina ni a otro ningún pariente. Habían transcurrido 22 años entre el primero y el segundo testamento, y es probable que durante ese tiempo la comunicación con Portugal se hubiere distanciado, lo que

60 Ibídem, ff. 698v-699.

61 Hemos encontrado sólo un caso de relación entre lusitana e india. Se trató de Juana de Melo quien, en 1620, mandó 20 pesos de a ocho reales "a Juana hija de una india que se [llama] María de Melo [...] para sus necesidades". Cfr. Testamento de Juana de Melo. Lima, 20-XI-1620. AGN, Prot. Not. 832, Francisco Hernández (1620), f. 2423v.

62 Para una referencia de este último caso, véase: Testamento de María de Cabrera. Lima, 16-VIII-1621. AGN, Prot. Not. 59, Cristóbal de Aguilar Mendieta (1621), ff. 489-489v.

63 Cfr. Testamento de Catalina de Acuña. Lima, 1-IV-1646. AGN, Prot. Not. 2067, Registros sueltos, Tomás de Mansilla (1646), f. 29v.

64 Cfr. Testamento de Luisa de Jesús Fernandes. Lima, 1631. AGN, Prot. Not. 1923, Gerónimo de Valencia (1631), f. 260 . 
evidenciaría, por otro lado, una mayor cercanía y arraigo -para este caso específicocon la tierra de adopción ${ }^{65}$.

\section{DESCENDENCIA FEMENINA E INSERCIÓN SOCIAL}

Aparte de los casos expuestos hemos incorporado en este estudio algunas referencias de otras mujeres que, aunque habían nacido en Lima, tenían ascendencia portuguesa. Es probable que para muchos de los inmigrantes lusos los hijos habidos en el Perú representaran otra forma de alcanzar -o consolidar más bien- su posición e integración en el medio local. En este contexto debió adquirir especial relevancia la presencia de las hijas quienes -ya como religiosas o como casadas- habrían fortalecido los vínculos del progenitor con las instituciones civiles y religiosas de la capital.

Desde el punto de vista jurídico los hijos de los portugueses -y en general de los extranjeros- nacidos en el Perú eran reputados por naturales del reino. Por cédula de 14 de agosto de 1620 la corona española reconocía, en efecto, como naturales del reino a todos los nacidos en España de padres extranjeros ${ }^{66}$. Esta situación afectó también a los nacidos en América, puesto que las Indias, de acuerdo con Rafael Antúnez y Acevedo, "desde su descubrimiento y conquista se agregaron con igual derecho a la Corona de Castilla" ${ }^{67}$. Concurrían en este caso las mismas calidades que con los nacidos en España. Se entiende que tal reconocimiento formal no sólo afectó a los criollos lusos que habían nacido en el Perú ${ }^{68}$, sino también a los progenitores que, aunque extranjeros, en la práctica habrían manifestado su intención de echar raíces, y por tanto de hacer duradera, estable o definitiva su permanencia en la nueva tierra ${ }^{69}$.

Una de estas criollas lusas fue doña Mariana Barreto, hija legítima de Nuño Rodrigues Barreto, natural de la isla de Madeira, y de Mariana de Castro, probablemente también portuguesa. Ambos se hallaron en el Perú desde mediados del siglo $\mathrm{XVI}^{70}$,

65 Las portuguesas de la muestra conservaron pocos recuerdos de Portugal. La referencia a San Antonio de Padua, santo portugués, aparece en un solo testamento; por otro lado, ninguna declaró estar en posesión de cartas o libros en lengua portuguesa, lo que hubiere sugerido otras formas de conservación de los primeros afectos. No obstante, conviene anotar que otros estudios, sobre los mercaderes portugueses procesados por la Inquisición, revelan -a través de la correspondencia privada- que no fueron pocos los que conservaron en su casa "una memoria viva de Portugal y lazos que se renovaban con los parientes ausentes". Sobre esto último, véase Ventura, 2005, v.I, t.I, pp. 347-457.

66 RLI, 1841 [1680], lib.IX, tít.XXVII, ley XXVII, t.IV, p. 15.

67 ANTÚNEZ, 1981 [1797], parte V, art. IV, p. 297.

68 El término criollo será utilizado en este trabajo en el sentido en que aparece en la documentación, es decir, para hacer referencia al hijo de portugueses -o que al menos uno de los progenitores lo fuera- nacido en el Perú. Para una aproximación al concepto de criollo para el tiempo que nos ocupa, véase ArRom, 1951, pp. 172-176.

69 Sobre la integración de los extranjeros, de sus compromisos y lealtades, a partir de la vecindad, en la España de la Edad Moderna, véase Herzog, 2006, pp. 47-79.

70 Al parecer Nuño Rodrigues Barreto "fue uno de los primeros pobladores y pacificadores de las provincias del Perú en tiempos de las rebeliones de Gonzalo Pizarro y [...] Hernández Girón”. De ser así, aunque su condición fuera de extranjero, es probable que las autoridades virreinales lo hubieran reconocido legalmente por vecino del Perú, pues de acuerdo con la legislación indiana -en relación con las composiciones- Felipe II ordenó que se dispensara discretamente a los extranjeros que hubieren servido en los descubrimientos o en la pacificación y que estuvieren casados y con hijos y nietos, "aunque tengan la calidad de extranjería", en esta 
y juntos habían alcanzado la vecindad en Lima, y fundado -en esta ciudad- una próspera y numerosa familia. De los 15 hijos habidos en legítimo matrimonio habían sobrevivido -por lo menos hasta 1596-, 11 de ellos -seis varones y cinco mujeres-, entre los que se encontraba nuestra protagonista ${ }^{71}$. En efecto, Mariana Barreto, natural y vecina de la Ciudad de los Reyes, integró una de las familias más numerosas -y también de las más influyentes- de la capital, y es probable que entre los planes queridos para cada uno de los hijos, Rodrigues Barreto hubiere considerado para esta hija suya en particular el matrimonio como medio de promoción económico-social. Consta en la documentación que de las cinco hijas legítimas ${ }^{72}$, dos estuvieron destinadas al matrimonio: Mariana Barreto había casado con el almirante Lope de la Vega, e Isabel Barreto, con el adelantado Álvaro de Abendaño ${ }^{73}$. En ambos casos se trató de matrimonios ventajosos para la familia, por cuanto los dos consortes ostentaban el grado militar de almirante o el título dignatario de adelantado, que unidos a su fortuna o prebendas personales ${ }^{74}$, y a la posibilidad de obtener -a partir de expediciones militares- alguna gobernación, suponía en definitiva que la familia entera recibiera no sólo beneficios económicos con los "aprovechamientos" de esas gobernaciones, sino también "calidad y honra", se entiende por el matrimonio con dichos adelantados ${ }^{75}$.

Es probable que Mariana Barreto hubiere recibido una dote importante al momento de casar con el almirante Lope de la Vega, en testamento dictado en 1608 declaró tener en arrendamiento un pedazo de viña en el valle de Umay, término de Ica, "que lo hube y heredé de los dichos mis padres en la partición que se hizo entre mis her-

situación debió hallarse nuestro personaje. Cfr. MelLÉN, 2008, p. 105; RLI, 1841 [1680], lib.IX, tít.XXVII, ley XIII, p. 14, respectivamente.

71 Utilizaremos el nombre de Mariana Barreto para referirnos a esta mujer, teniendo en cuenta su rúbrica en el testamento dictado en 1608, no obstante que en otras referencias documentales se utilice el nombre de Mariana de Castro para aludir a la misma mujer. Cfr. Testamento de Mariana Barreto. Lima, 10-II-1608. AGN, Prot. Not. 181, Cristóbal Barrientos (1608), ff. 396-399v.

72 Nuño Rodrigues Barreto reconoció además una hija natural, "Blanca Barreto, mujer de Pedro Méndez de Sotomayor", que la hubo antes de su matrimonio con Mariana de Castro. Cfr. Bienes de difuntos: Nuño Rodrigues Barreto. 1598. AGI, Contratación, 253, n.1, r.13, ff. 6v-7.

73 Hemos optado por utilizar el nombre de Álvaro de Abendaño porque así aparece en la documentación consultada, no obstante que en los varios trabajos publicados sobre Isabel Barreto la referencia a este adelantado sea el de Álvaro de Mendaña. Para una aproximación a la vida y genealogía de Isabel Barreto, donde se incluye -lo más valioso- la transcripción del testamento de la susodicha, véase MelléN, 2008, pp. 101-116. Para otros estudios breves sobre la misma mujer, pero referidos a su expedición a través del Pacífico, véase MaURA, 2005, pp. 213-219; Gómez-LuCENA, 2013, pp. 103-120. En este último trabajo se parte de una errónea consideración sobre el origen y naturaleza de esta familia -Barreto- en su relación con el Perú.

${ }^{74}$ Se conoce que a la muerte de Álvaro de Abendaño, Isabel Barreto heredó -en segunda vida- unas rentas "de los tributos de Tiahuanaco", que pertenecían al susodicho, cuyo valor anual era de 3.000 pesos. Por su parte Mariana Barreto recurriría "ante el alcalde de Lima una curaduría que [había pertenecido] a su marido". Cfr. MELLÉN, 2008, pp. 107, 112-113.

75 Esta valoración del matrimonio como beneficio para toda la familia queda reflejada en las palabras del padre cuando declara haber entregado a su hija Isabel Barreto una dote de 40.000 ducados cuando la casó con el adelantado Álvaro de Abendaño. Pedirá al resto de sus hijos legítimos, herederos en el testamento, "no se le pidan ni demanden cosa alguna a la dicha mi hija ni al dicho su marido", por cuanto "todos recibimos muncha calidad y honra en haberse casado el dicho adelantado con ella", añadía que "el dicho adelantado llevó en su compañía cuatro hijos míos para la honrar y aprovechar en su gobernación". Bienes de difuntos de Nuño Rodrigues Barreto. 1598. AGI, Contratación, 253, n.1, r.13, ff. 6v-7. 
manos y [yo]"76. Esta pareja de esposos habría participado en 1595 de la expedición de Álvaro de Abendaño en su ruta hacia las míticas islas Salomón. El viaje representaría un duro revés para Mariana Barreto, puesto que el navío Santa Isabel que iba al mando de su marido "se perdió y nunca de él se ha sabido"77. Ya viuda regresó al Perú donde la encontraremos -en 1608- como vecina y moradora de la Ciudad de los Reyes.

En esta ciudad, Mariana Barreto consolidó su posición como mujer independiente en términos económicos. Sabemos que no volvió a casar ni dejó hijo alguno a la posteridad; vivía en compañía de su esclava Lorenza, mulata de 13 años de edad, que "nació en mi casa y la he criado y le tengo mucho amor y voluntad", y de un esclavo Joan de casta nalu, de más de 40 años, que tenía para su servicio. Sus mayores ingresos seguramente procedieron de las rentas percibidas del "pedazo de viña" que había alquilado, y es probable que realizara también pequeñas transacciones con "algunas personas", de las que tenía -en 1608- una deuda por pagar de 40 patacones. $\mathrm{Su}$ hacienda no fue poca, puesto que, al menos, contempló la posibilidad, "si sus bienes alcanzaren", de fundar una memoria o capellanía de misas por su ánima. Por otro lado, supo crear y mantener vínculos afectivos con la Orden de San Francisco, ya fuere a través de su confesor, fray Antonio de León, a quien encargó ejecutara "lo que con él tengo tratado y comunicado", o porque escogiera la iglesia del convento grande para su entierro, y para el cumplimiento de las "cincuenta misas de sufragio" que había dejado señaladas en el testamento ${ }^{78}$. Se entiende que si bien el convento de San Francisco representó, en el siglo XVII, el principal lugar de enterramiento en Lima $^{79}$, no es menos cierto que su elección suponía -por parte del interesado- de una mayor inversión de capital.

Cuando Mariana Barreto dictó testamento en 1608, sus padres eran ya difuntos, pero la mayoría de sus hermanos -al menos ocho de ellos- vivían aún, en Lima o en otras ciudades próximas a la capital, según se deduce del testamento otorgado por su hermana Isabel en $1612^{80}$. A diferencia de ésta que supo incluir a los hermanos en la expresión de su última voluntad, ninguno, sin embargo, será mencionado en la escri-

76 Testamento de Mariana Barreto. Lima, 10-II-1608. AGN, Prot. Not. 181, Cristóbal Barrientos (1608), ff. $397-397 \mathrm{v}$.

77 La referencia a la pérdida de este navío se recoge en el testamento de Isabel Barreto dictado en 1612 , véase la transcripción del mismo en: Mellén, 2008, pp. 112-115. Para una amplia relación de los sucesos de esta expedición que tuvo por protagonistas a Álvaro de Abendaño y a su esposa Isabel Barreto, véase QUEIRos, 2000 .

78 Testamento de Mariana Barreto. Lima, 10-II-1608. AGN, Prot. Not. 181, Cristóbal Barrientos (1608), ff. 396-399v.

79 Benjamín Gento Sanz al explicar la evolución arquitectónica de esta iglesia refiere el problema que se planteó, para la seguridad física del templo, la apertura de nuevos sepulcros, esto hacia 1617. GENTO, 1945, pp. 121-126.

80 En ese año vivían todavía Petronila de Castro, Leonor de Castro, Beatriz de Castro, Diego Barreto, Luis Barreto, Gerónimo Barreto y Antonio Barreto. Los dos últimos serán nombrados, en el testamento de doña Isabel, como albaceas; y todos recibieron de esta hermana suya, alguna donación o limosna generosa. No se menciona el nombre de doña Mariana, porque probablemente, para ese año (1612), era ya difunta. Cfr. Testamento de Isabel Barreto. Castrovirreyna, 15-VII-1612. Library of Congress: The Harknees Collection, documentos 950-953, ff. 546-549v, apud Mellén, 2008, pp. 112-115. No nos ha sido posible -de momentoconsultar el documento original. 
tura testamentaria de doña Mariana ${ }^{81}$. Es probable que a su regreso al Perú, y después de la nefasta experiencia de 1595, Mariana Barreto decidiera llevar una vida menos azarosa que la elegida por doña Isabel ${ }^{82}$. Recogida en la tranquilidad de su casa dirigió desde allí la administración de sus rentas, procedentes -en su mayoría- de la herencia recibida de sus padres. Alejada de los hermanos, que seguramente tenían sus propios afanes, familia y fortuna, cultivó estrecha amistad -sobre la base de la confianza- con Benito de Salvatierra, procurador de la Real Audiencia, y con su familia. Precisamente Salvatierra y doña Bernarda de Vera, su mujer, serán nombrados albaceas y tenedores de bienes en el testamento. Por otro lado, conviene tener en cuenta que doña Mariana Barreto habría ocupado una posición secundaria con respecto a su hermana Isabel, en cuyo contrato de dote se estipuló parte del financiamiento de la expedición de 1595, y la participación -en ella-, de al menos cuatro hermanos suyos ${ }^{83}$. Se entiende así que en virtud de ese contrato, y del compromiso asumido con su padre por tan generosa dote -40.000 ducados-, doña Isabel hubiere sentido la necesidad y la obligación de velar por la seguridad y el bienestar de la familia, tal y como se recoge en el testamento que dictó en 1612.

Mariana Barreto, por su parte -y sin hijos legítimos a quienes legar los bienes heredados o los adquiridos en vida- decidió perennizar su nombre y memoria a través de una fundación perpetua. Nombró por heredera su ánima, y dejó señalado en el testamento, "si sus bienes alcanzaren", la fundación de una memoria y capellanía de misas, para cuyo efecto instituyó por patrón al dicho Benito de Salvatierra. A este procurador le fue confiada la fundación, el nombramiento de capellán, y la designación de los patronos que habrían de sucederle, siempre que fueran elegidos de entre los hijos y deudos del susodicho, y de los descendientes de éstos; en caso de que no hubiera tales hijos y deudos, dejó establecido que se nombrara por patrona de la dicha capellanía a doña Bernarda de Vera. El círculo íntimo de nuestra criolla portuguesa había quedado así reducido a muy pocas personas, descontando la comunicación habida con su confesor, sus tratos se dieron de forma casi exclusiva con la familia del procurador. De sus bienes muebles destinó a doña Inés Salvatierra, hija del susodicho, todo lo que se hallare en un escritorio de costura "de sarcillos, cintillos, cosas de costura y demás menudencias", por razón del afecto y "de la mucha amistad" que le unía a la familia ${ }^{84}$. La enumeración de los bienes relacionados con la indumentaria sugiere, por otro lado, que Mariana Barreto vistió -y calzó- con elegancia, pero sin ostentación. La mayor parte de su ropa -que al momento del inventario se hallaba rota y raída-, se había confeccionado sobre finas telas: tamenete, jergueta o tafetán. Unos chapines nuevos con tiras de plata adornaban sus pies, y es probable que el faldellín de tamenete nuevo con su sayón de oro -conservado en su recámara- fuera lucido en alguna ocasión especial.

81 Había, también, sobrinos y sobrinas -hijos de algunos de sus hermanos- que tampoco serán recordados, entre otros los hijos de don Antonio Barreto, además de doña Florencia y doña Mariquita, esta última era hija de Petronila de Castro. Ibídem, pp. 114-115.

82 Ibídem, pp. 112-115.

83 Bienes de difuntos de Nuño Rodrigues Barreto. 1598. AGI, Contratación, 253, n.1, r.13, ff. 6v-7v.

84 Testamento de Mariana Barreto. Lima, 10-II-1608. AGN, Prot. Not. 181, Cristóbal Barrientos (1608), ff. $396 \mathrm{v}-397,398$. 
Los planes matrimoniales que Nuño Rodrigues Barreto había querido para estas dos hijas suyas, doña Mariana y doña Isabel, revelan su intención de fortalecer los vínculos con la ciudad que le había acogido; quiso asegurar -con estos enlaces ventajosos-, un futuro promisorio tanto para ellas como para sus descendientes, y que lógicamente estos bienes alcanzaran también a los otros miembros de la familia; se entiende con el resultado de las expediciones emprendidas por sus dos yernos. Esta posibilidad de consolidación e integración de la familia con el medio local, a través de matrimonios provechosos, podríamos entenderla -tal y como habría sido pensada por el padre-, como una estrategia de carácter económico, pero no sería la única vía. Nuño Rodrigues Barreto había reservado para otra de las hijas, doña Beatriz de Castro, su entrada en religión como monja profesa en el monasterio de la Limpia Concepción. Es probable que la hubiera dotado generosamente; y a través de codicilo dictado en Lima el 20 de abril de 1596, mandará "que de sus bienes y haciendas y de lo más bien parado de ellas se le den [otros] doscientos pesos de plata corriente de renta en cada un año [...] para sus gastos y necesidades" ${ }^{95}$. La entrada en religión suponía para la familia -además de una inversión- que al menos una de sus intengrantes estaría rezando por ellos y actuando de "intercesora del clan familiar ante la divinidad" 86 . Por otro lado, representó un signo de honor y prestigio, por cuanto se entendía -para ese tiempo- que la hija monja "ligaba a la familia [de la élite] con los cielos"87.

Rodrigues Barreto moriría probablemente en 1596, por tanto no pudo ver el resultado de sus proyectos. Le habían quedado dos hijas doncellas: Petronila de Castro y Leonor de Castro. La primera casaría con Pedro Bustamante; la segunda -como su hermana Beatriz- entraría de monja en el monasterio de la Concepción de Lima. Ya viuda doña Petronila -de quien sabemos fue la única de las hermanas que tuvo descendencia directa- se retiraría al convento de Santa Clara, el mismo que unos años más tarde fuera elegido por doña Isabel como morada del cuerpo una vez que le llegara la muerte ${ }^{88}$. De los hijos varones hemos podido conocer que tres de ellos habían participado de la expedición de 1595; los otros tres seguramente tomaron rumbos diferentes, pero está claro que buena parte del proyecto económico- familiar querido por el jefe de familia se había basado en el matrimonio provechoso de las hijas, como estrategia de unidad y solidaridad familiar, consolidación del nombre, y preservación del patrimonio, pruebas ineludibles de la asimilación alcanzada por una familia de origen extranjero con el medio.

\section{CONSIDERACIONES FINALES}

La revisión de las fuentes notariales del Archivo General de la Nación de Perú nos ha permitido constatar la escasa presencia de la mujer entre los inmigrantes lusos que se establecieron en Lima en los años de 1600 a 1680. El proceso migratorio hacia el

85 Codicilo de Nuño Rodrigues Barreto. Lima, 20-IV-1596. AGN, Prot. Not. 55, Diego Gómez Baeza (1596), ff. 747-747v.

86 SÁnCHEZ-CONCHA, 2013, p. 327.

87 VAn Deusen, 2007, p. 188.

88 Para esta información véase MELLÉN, 2008, pp. 106-107. 
Nuevo Mundo habría atraído principalmente a los varones -por razón de su oficio, interés económico o por el simple afán de aventura-, quedando las mujeres, especialmente las casadas, en el país ibérico, y a la espera, seguramente, de ser llamadas por el marido ausente. De las que sí lograron cruzar el Atlántico se ha podido conocer que en su mayoría eran viudas, lo cual permite sugerir que probablemente el matrimonio había tenido lugar en suelo americano, como fue el caso ya citado de Leonor de Melo, cuya escritura de dote se firmó en la ciudad de Panamá.

Las mujeres lusas, materia del presente estudio, habrían conformado los estratos medios de la sociedad, es decir, que no fueron ni ricas ni pobres, aunque sus relaciones sociales sí se habrían dado con instituciones de claro acceso a sectores privilegiados: monasterios, cofradías y órdenes religiosas. Su interés por las cosas de Dios y por la salvación del alma queda reflejado precisamente en la elección de sepultura particular dentro de las capillas de los conventos, en su ingreso como hermanas -o cofrades- en las instituciones religiosas y en la inversión generosa de parte de su hacienda en misas de sufragio y obras pías. Esta realidad se explica también porque en la mayoría de los casos conocidos no hubo hijos legítimos en el matrimonio ni herederos forzosos en el testamento.

Si bien desde el punto de vista jurídico, las mujeres lusas eran tenidas por extranjeras, ello no dificultó el que pudieran cumplir su proyecto de vida en la capital virreinal. Con excepción de la esclava, cuya presencia en la ciudad obedeció a razones distintas, el resto de las mujeres habría llegado en un viaje planificado, es decir, que no respondió a la mera aventura, como se deduce del pequeño capital del que dispusieron, la presencia de otros parientes en su entorno cercano, y sobre todo por la concepción del matrimonio como estrategia formal de integración. Eran extranjeras, pero su comportamiento en el medio local fue el de vecinas moradoras, o simplemente el de vecinas, que llegaron a la ciudad para quedarse de modo definitivo en ella. No hemos encontrado, por otro lado, testimonios de que alguna hubiere deseado -o intentado- el regreso a la patria de origen, más bien se ha podido conocer que fueron pocos los recuerdos conservados de Portugal, y muy escasas las referencias a alguna manda destinada a la tierra natal.

En lo económico destacaron en el pequeño comercio, algunas comprando, vendiendo o alquilando algunas piezas de esclavos; otras como prestamistas, pero sobre todo queremos subrayar su papel como mujeres independientes, cabezas de familia que supieron gestionar y administrar sus bienes y negocios. Aunque algunas se valieron de agentes o representantes cuando los negocios tenían lugar en Tierra Firme o en los reinos de España -caso de Leonor de Melo-; en otros -como el de Luisa de Jesús Fernandes- eran ellas quienes hacían figurar sus nombres en las escrituras de compra-venta. Pocas fueron las propietarias de bienes inmuebles, tal posibilidad quedó reservada a las mujeres que tuvieron descendencia directa, se entiende pues que quienes se hallaron solas, aunque en compañía de ahijadas o esclavas que habían criado, prefirieran vivir del alquiler de casas o en aposentos dentro de una casa familiar.

Poco fecundas fueron nuestras lusas: de las cinco casadas sólo dos habían tenido hijos legítimos. Catalina de Acuña era la madre del escribano Francisco de Acuña, quien hacia mediados del siglo XVII había protocolizado diversas escrituras notariales de gente de nación portuguesa. Por su parte, Leonor de Melo, quien declaró cuatro 
hijos legítimos -uno de ellos enfermo y tullido-, era la madre de Pedro Gerónimo de Melo, importante comerciante de esclavos y de géneros de Castilla en la ruta de Lima- Tierra Firme- España, en los años veinte del siglo XVII. Los hijos habidos en el Perú, aunque de padres extranjeros, eran tenidos -desde el punto de vista jurídico- por naturales del reino, y en cierto modo representaron para los casos citados la prolongación del nombre de los progenitores, y la confirmación evidente de que éstos habían procurado la integración -o asimilación- en la tierra de acogida.

En este sentido, el caso de Mariana Barreto y el de su hermana Isabel revelan las estrategias practicadas por el patriarca para consolidar la posición de la familia en el contexto de la sociedad limeña que se aprestaba a entrar a una nueva centuria. Es probable que en el caso de Nuño Rodrigues Barreto -tenido por "uno de los primeros pobladores y pacificadores de las provincias del Perú en tiempos de las rebeliones de Gonzalo Pizarro y [...] Hernández Girón" ${ }^{89}$, y que en virtud de ello había recibido alguna merced de la corona española, no hubiere hecho falta demostrar su intención de ser vecino de la ciudad; al contrario, habría gozado de cierto reconocimiento social, pero no había dejado de ser portugués. Fue su voluntad que el prestigio social del que gozó y la hacienda que administró alcanzara a sus descendientes, que estos pudieran acrecentar las rentas o la parte de la herencia que les había sido legadas. Los matrimonios provechosos de las hijas, el financiamiento dado a la expedición emprendida por uno de los yernos en el que tomaron parte cuatro hijos suyos, o la entrada en religión de las hijas menores, evidencian su interés de afianzar el nombre y la memoria en la ciudad. De las hijas sólo una tuvo descendencia; y de otras dos sabemos -por el testamento dictado- que buena parte de la hacienda estuvo destinada a fundaciones perpetuas.

Finalmente valoramos el aporte de la fuente notarial como medio para explorar la presencia de los extranjeros en el Perú virreinal, y en este caso concreto el de las mujeres lusas en la capital. Si bien existen algunos estudios sobre las mujeres en América, creemos que aún falta mucho por escribir sobre la mujer extranjera. Aunque los datos aportados en este trabajo no permiten arribar a conclusiones definitivas ni plantear generalizaciones, sí dejan constancia de la apertura de la América hispana, también para ese otro género de los no naturales del reino.

\section{REFERENCIAS BIBLIOGRÁFICAS}

ANTÚNEZ Y ACEVEDo, Rafael

1981 Memorias Históricas sobre la legislación y gobierno del comercio de los españoles con sus colonias en las Indias Occidentales [1797], edición facsímil, presentación y estudio preliminar de Antonio García-Baquero González. Madrid. Instituto de Estudios Fiscales.

Arrom, José Juan

1951 "Criollo: definición y matices de un concepto". Hispania, Madrid, vol. 34/2, pp. 172176.

89 Mellén Blanco, 2008, p. 105. 
BouzA, Fernando

1998 Imagen y propaganda. Capítulos de historia cultural del reinado de Felipe II. Madrid. Akal.

Cook, Noble David

1968 "Introducción”. En Padrón de indios de Lima en 1613 [transcripción]. Lima. Seminario de Historia Rural Andina, pp. I-XIII.

D'ARMADA, Fina

1995 “As mulheres nas naus da India (sec. XVI)". En O rostro feminino da expansão portuguesa. Lisboa. Comissão para a Igualdade e para os Direitos das Mulheres, pp. 197-230.

DurÁn Montero, María Antonia

1994 Lima en el siglo XVII, arquitectura, urbanismo y vida cotidiana. Sevilla. Diputación Provincial de Sevilla.

ENCINAS, Diego de

1945 Cedulario Indiano [1596]. Reproducción facsímil de la edición única de 1596, con estudio e índices de Alfonso García Gallo. Madrid. Cultura Hispánica.

Galbis DiEz, Carmen

1986 Catálogo de pasajeros a Indias durante los siglos XVI, XVII y XVIII. V. 6. Madrid. Espasa Calpe. Ministerio de Cultura, Dirección de Bellas Artes, Archivos y Bibliotecas.

GÁLVEz Ruiz, María Ángeles

1997 “Emigración a Indias y fracaso conyugal”. Chronica Nova, Granada, n 24, pp. 79102.

García de Proodian, Lucía

1966 Los judios en América. Sus actividades en los Virreinatos de Nueva Castilla y Nueva Granada. S. XVII. Madrid. Consejo Superior de Investigaciones Científicas-Instituto Arias Montano-Seminario de Estudios Americanistas de la Universidad de Madrid.

Gento SAnz, Benjamín

1945 San Francisco de Lima. Estudio histórico y artístico de la iglesia y convento de San Francisco de Lima. Lima. Imprenta Torres Aguirre.

Gómez-LuCENA, Eloísa

2013 Españolas del Nuevo Mundo. Ensayos biográficos, siglo XVI-XVII. Madrid. Cátedra.

Herzog, Tamar

2006 Vecinos y extranjeros. Hacerse español en la Edad Moderna. Madrid. Alianza Editorial.

Hespanha, António M

1995 “O estatuto jurídico da mulher na época da expansão”. En O rostro feminino da expansão portuguesa. Lisboa. Comissão para a Igualdade e para os Direitos das Mulheres, pp. 53-64.

Hutchinson, Amélia P.

1995 "Dea ou Deabu? -O Declínio das Relações masculino-femenino como reflexo do declínio do Império". En O rostro feminino da expansão portuguesa. Lisboa. Comissão para a Igualdade e para os Direitos das Mulheres, pp. 181-186. 
KLAWE, Janina Z

1995 "O papel das mulheres nos descobrimentos e na expansão portuguesa". En O rostro feminino da expansão portuguesa. Lisboa. Comissão para a Igualdade e para os Direitos das Mulheres, pp. 253-258.

KonetzKe, Richard

1945a“La emigración de mujeres españolas a América durante la época colonial”. Revista Internacional de Sociología. Madrid, vol. III/9-10, pp. 123-150.

1945b "Legislación sobre inmigración de extranjeros en América durante la época colonial”, Revista Internacional de Sociología. Madrid, vol. III/11-12, pp. 269-299.

LATASA VASSALlo, Pilar

1997 Administración virreinal en el Perú: gobierno del marqués de Montesclaros (16071615). Madrid. Editorial Centro de Estudios Ramón Areces.

LóPEz de CARAVANTES, Francisco

1986-1987 Noticia General del Perú, v. 2-3. Madrid. Ediciones Atlas.

LÓPEZ DE MARISCAL, Blanca

2013 “El viaje a la Nueva España entre 1540 y 1625: el trayecto femenino". En Historia de la mujeres en América Latina [2002]. Copia digital de la primera edición. Murcia. Universidad de Murcia, pp. 73-87. En http://www.um.es/estructura/unidades/uigualdad/intranet/docs/historia-de-las-mujeres-en-america-latina.pdf.

LóPez- SALAzAR CODES, Ana Isabel

2010 Inquisición portuguesa y monarquía hispánica en tiempos del perdón general de 1605. Lisboa. Colibrí.

MannAelli, María Emma

2004 Pecados Públicos. la ilegitimidad en Lima, siglo XVII. Lima. Flora Tristán.

MaUra, Juan Francisco

2005 Españolas de Ultramar en la Historia y en la Literatura. Valencia. Universitat de València.

MeA, Elvira Azevedo

1995 "Mulheres nas teias das expansão". En O rostro feminino da expansão portuguesa. Lisboa. Comissão para a Igualdade e para os Direitos das Mulheres, pp. 65-75.

MedinA, José Toribio

1887 Historia del Tribunal del Santo Oficio de la Inquisición de Lima (1569-1820), vol. 2. Santiago de Chile. Imprenta Gutenberg.

Mellén Blanco, Francisco

2008 "La genealogía de doña Isabel Barreto, una mujer que atravesó el Pacífico en el siglo XVI". En LuQue Talaván - Manchado López (coords. y eds.), Un océano de intercambios: Hispanoasia (1521-1898). Homenaje al profesor Leoncio Cabrero Fernández, t. I. Madrid. Agencia de Cooperación Internacional, pp. 101-116.

Miceli, Paulo

1995 “'O zelo da virtude contra a peçonha do diabo'- Sospeitosas, virtuosas e impudentes: A visibilidade feminina nas viagens portuguesas á época dos descobrimentos". En $O$ rostro feminino da expansão portuguesa. Lisboa. Comissão para a Igualdade e para os Direitos das Mulheres, pp. 187-196. 
Moreno, Laudelino

1936 "Los extranjeros y el ejercicio del comercio en Indias". Colección de estudios históricos, jurídicos, pedagógicos y literarios. Homenaje a Rafael Altamira. Madrid, C. Bermejo, pp. 364-385.

Oтте, Enrique

1996 Cartas privadas de emigrantes a Indias, 1540-1616. México. Fondo de Cultura Económica.

Ponce LeIva, Pilar

2011 “"Por el mucho amor que les he tenido...'. Sensibilidades y dinámicas sociales en Quito a mediados del siglo XVII". En BernabéU - LANgue (coords.), Fronteras y sensibilidades en las Américas. Madrid, Aranjuez. Doce Calles, pp. 21-44.

Ponce LeIva, Pilar - Amadori, Arrigo

2008 "Redes sociales y ejercicio del poder en la América Hispana: consideraciones teóricas y propuestas de análisis". Revista Complutense de Historia de América. Madrid, $\mathrm{n}^{\mathrm{o}} 34$, pp. 15-42.

QueIros, Pedro Fernandes de

2000 Historia del Descubrimiento de las regiones Austriales hecho por el general Pedro Fernández de Quirós. Edición de Justo Zaragoza. Madrid. Dove.

Recopilación de Leyes de los reinos de las Indias, mandadas imprimir y publicar por la Majestad Católica de Rey Don Carlos II [1680], $5^{\circ}$ ed., 4 t. Madrid. Boix. (1841).

Romera Iruela, Luis - Galbis Diez, Carmen

1980 Catálogo de pasajeros a Indias durante los siglos XVI, XVII y XVIII. vol. 5, t.I. Madrid. Espasa Calpe. Ministerio de Cultura, Dirección de Bellas Artes, Archivos y Bibliotecas.

SALINAS Y CóRDOVA, Buenaventura de

1631 Memorial de las Historias del Nuevo Mundo Perú. Méritos y excelencias de la Ciudad de Los Reyes. Lima. Gerónimo de Contreras.

SÁNCHEZ-CONCHA BARRIOS, Rafael

2013 Del régimen hispánico. Estudios sobre la conquista y el orden virreinal peruano. Arequipa. Universidad Católica San Pablo, pp. 293-343.

SÁNCHEZ RuBio, Rocío - TesTón NúÑEz, Isabel

1999 El hilo que une. Las relaciones epistolares en el Viejo y el Nuevo Mundo (siglos XVIXVIII). Mérida. Universidad de Extremadura. Servicio de Publicaciones.

Sullón BARreto, Gleydi

2015 Vasallos y extranjeros. Portugueses en la Lima virreinal, 1570-1680. Madrid. Universidad Complutense de Madrid. Servicio de Publicaciones.

TESTÓN NúÑEZ, Isabel - SÁNCHEZ RUBIO, Rocío

2010 "Identidad fingida y migraciones atlánticas (siglos XVI-XVIII)". En Un juego de engaños. Movilidad, nombres y apellidos en los siglos XV a XVIII. Estudios reunidos y presentados por Gregorio Salinero e Isabel Testón Núñez. Madrid. Casa de Velázquez, pp. 87-101.

Transcripción de las ordenanzas de Descubrimiento, nueva población y pacificación de las Indias dadas por Felipe II, el 13-VII-1573, en el Bosque de Segovia, según el original que se conserva en el Archivo General de Indias, edición facsímil. Madrid. Ministerio de la Vivienda, Servicio Central de Publicaciones. (1973 ). 
VALladARES, Rafael

2008 La conquista de Lisboa. Violencia militar y comunidad política en Portugal, 15781583. Madrid. Marcial Pons Historia.

VAn Deusen, Nancy E.

2007 Entre lo sagrado y lo mundano. La práctica institucional y cultural del recogimiento en la Lima virreinal. Lima. Pontificia Universidad Católica del Perú. Instituto Francés de Estudios Andinos.

Veitia Linage, José de

1981 Norte de la Contratación de las Indias Occidentales [1672], edición facsímil de la editada en Sevilla en 1672. Madrid. Instituto de Estudios Fiscales.

Ventura, Maria da Graça A. Mateus

2005 Portugueses no Peru ao Tempo da União Ibérica: mobilidade, cumplicidades e vivência, 3 vols. Lisboa. Imprensa Nacional, Casa da Moeda. 